\title{
The state of nutrition care in outpatient hemodialysis settings in Malaysia: a nationwide survey
}

\author{
Ban-Hock Khor ${ }^{1}$, Karuthan Chinna², Abdul Halim Abdul Gafor ${ }^{3}$, Zaki Morad ${ }^{4}$, Ghazali Ahmad ${ }^{5}$, Sunita Bavanandam5, \\ Ravindran Visvanathan ${ }^{5}$, Rosnawati Yahya ${ }^{5}$, Bak-Leong Goh ${ }^{6}$, Boon-Cheak Bee ${ }^{7}$ and Tilakavati Karupaiah ${ }^{1,8^{*}}$ (D)
}

\begin{abstract}
Background: This study aimed to assess the situational capacity for nutrition care delivery in the outpatient hemodialysis (HD) setting in Malaysia by evaluating dietitian accessibility, nutrition practices and patients' outcomes.

Methods: A 17-item questionnaire was developed to assess nutrition practices and administered to dialysis managers of 150 HD centers, identified through the National Renal Registry. Nutritional outcomes of 4362 patients enabled crosscutting comparisons as per dietitian accessibility and center sector.

Results: Dedicated dietitian (18\%) and visiting/shared dietitian (14.7\%) service availability was limited, with greatest accessibility at government centers (82.4\%) > non-governmental organization (NGO) centers (26.7\%) > private centers (15.1\%). Nutritional monitoring varied across HD centers as per albumin (100\%) > normalized protein catabolic rate (32. $7 \%)>$ body mass index (BMl, 30.7\%) > dietary intake (6.0\%). Both sector and dietitian accessibility was not associated with achieving albumin $\geq 40 \mathrm{~g} / \mathrm{L}$. However, NGO centers were $36 \%$ more likely $(p=0.030)$ to achieve pre-dialysis serum creatinine $\geq 884 \mu \mathrm{mol} / \mathrm{L}$ compared to government centers, whilst centers with dedicated dietitian service were $29 \%$ less likely $(p=0.017)$ to achieve pre-dialysis serum creatinine $\geq 884 \mu \mathrm{mol} / \mathrm{L}$. In terms of BMI, private centers were $32 \%$ more likely $(p=0.022)$ to achieve BMI $\geq 25.0 \mathrm{~kg} / \mathrm{m}^{2}$ compared to government centers. Private centers were $62 \%$ less likely $(p<0.001)$ while NGO centers were $56 \%$ less likely $(p<0.001)$ to achieve serum phosphorus control compared to government centers. Patients from centers with a shared/visiting dietitian had $35 \%$ lower probability $(p<0.001)$ to achieve serum phosphorus levels below $1.78 \mathrm{mmol} / \mathrm{L}$ compared to centers without access to a dietitian.
\end{abstract}

Conclusions: There were clear discrepancies in nutritional care in Malaysian HD centers. Changes in stakeholder policy are required to ensure that dietitian service is available in Malaysian HD centers.

Keywords: Dietitian, Hemodialysis, Nutrition practices, Survey, Oral nutrition supplement, In-center meals

\section{Background}

Malaysia is an upper middle-income country in Asia [1], where hemodialysis (HD) forms the main choice of renal replacement therapy for patients with end stage kidney disease compared to peritoneal dialysis and kidney transplant [2]. About 33,456 patients are on HD treatment as reported in 2015 with the proportion of delivery by

\footnotetext{
* Correspondence: tilly_karu@yahoo.co.uk

${ }^{1}$ Dietetics Program, Faculty of Health Sciences, Universiti Kebangsaan

Malaysia, 50300 Kuala Lumpur, Malaysia

${ }^{8}$ School of BioSciences, Faculty of Health and Medical Sciences, Taylor's

University, 1, Jalan Taylors, 47500 Subang Jaya, Malaysia

Full list of author information is available at the end of the article
}

sector changing dramatically over time [2]. The scenario of dialysis treatment has shifted from government-only providers to burden sharing with non-governmental organization (NGO) not for profit centers and more recently private centers have risen to become the largest provider in Malaysia [2].

Although HD treatment is life saving, this population is prone to multiple co-morbidities such as protein energy wasting (PEW), fluid and electrolytes imbalance, mineral bone disorders, and anemia due to dialysis and uremic-induced metabolic disruptions [3]. These comorbidities are potentially treated by medical nutrition

(c) The Author(s). 2018 Open Access This article is distributed under the terms of the Creative Commons Attribution 4.0 International License (http://creativecommons.org/licenses/by/4.0/), which permits unrestricted use, distribution, and reproduction in any medium, provided you give appropriate credit to the original author(s) and the source, provide a link to the Creative Commons license, and indicate if changes were made. The Creative Commons Public Domain Dedication waiver (http://creativecommons.org/publicdomain/zero/1.0/) applies to the data made available in this article, unless otherwise stated. 
therapy provided by dietitians practicing in nephrology care. Ideally the components of this therapy are implemented as per the standardized nutrition care process to ensure optimal nutrition outcomes [4]. Specifically, nutrition assessment is the first critical step of the nutrition care process as it calls for identification of nutrition-related issues of HD patients leading to formulation of the nutrition diagnosis, which then sets the stage for nutrition intervention [5].

The optimal ratio of dietitian to patients in nephrology care has been suggested to be 1:100 patients, not exceeding 150 [4]. However, dietitian services have been observed to be limited in Malaysia and nutritional management was primarily carried out by physicians and nurses [6]. Concurrent with this limitation, the National Renal Registry (NRR) of Malaysia has been annually reporting on nutritional status as assessed by body mass index (BMI) and serum albumin from 2003 [7]. Noticeably, based on these two parameters alone, annual malnutrition reportage for Malaysian HD patients with 10-year trends from 2006 to 2015 have shown an increasing trend from 46 to $62 \%$ with serum albumin $<4.0 \mathrm{~g} / \mathrm{L}$, in contrast to a decreasing trend of $\mathrm{BMI}<25 \mathrm{~kg} / \mathrm{m}^{2}$ from 71 to $61 \%$ [8]. This limited data does not identify PEW, a condition characterized by loss of body protein muscle mass and fuel reserves, and which is suggested to be the core of malnutrition linked to mortality $[9,10]$. Recently, 38.5\% of Malaysian HD patients were identified with PEW using the diagnostic criteria of the International Society of Renal Nutrition and Metabolism [11]. Given this background, we felt it was critical to examine the current state of dietitian accessibility and nutrition practices in Malaysian HD centers.

\section{Methods}

\section{Study design and sample}

This cross-sectional study involved HD centers from government, private and NGO sectors. Through random stratified sampling, 153 HD centers were selected from $667 \mathrm{HD}$ centers registered with the Malaysia NRR for the year 2015. This sampling ensured adequate representation of all states within Malaysia. Data collection was conducted via telephone interviews with the dialysis managers of participating HD centers from November 2015 to March 2016. In addition, we captured annual patient data of these centers for the year 2015 from the NRR database. The protocol for this study received ethical approval from the Research Ethics Committee, National University of Malaysia (NN-079-2015) and Medical Research Ethic Committee, Ministry of Health, Malaysia (NMRR-15-1245-27039).

\section{Questionnaire development}

A 17-item questionnaire was designed to assess nutrition care provision at HD centers (Additional file 1). Three renal dietitians and a senior dialysis nurse reviewed and established content validity for the questionnaire. The questionnaire consisted of 4 sections:

- Section 1: Characteristics of the HD center such as sector, number of patients, and presence of a dietitian.

- Section 2: Nutrition parameters routinely monitored for HD patients and healthcare professionals involved in delivery of nutrition education.

- Section 3: Recommendation, indications, contraindications, and provision of renal specific oral nutrition supplements (ONS).

- Section 4: Practice of eating and provision of in-center meal during dialysis.

\section{In-center meals provision}

In-center meals provided during the dialysis were examined for nutritional composition. Personal communications with dialysis managers and dietitians from HD centers providing in-center full meals were established to enable access to the menu and portion sizes of food served. Nutrient analysis was carried out using software Nutritionist Pro $^{\text {max }}$ 2.2.16 software (First DataBank Inc., 2004) with reference to the Malaysian [12] and Singapore Food Composition [13] databases.

\section{Statistical analyses}

Continuous variables with normal distribution were presented as means \pm standard deviations while skewed continuous variables were presented as median (interquartile range). Categorical variables were presented as frequency (percentage). Chi-square was used to identify associations between categorical variables. Independent $t$-test and one-way ANOVA were used to compare means of continuous variables for groups identified by sector and dietitian accessibility. Bonferroni post hoc test allowed for paired comparisons between groups. Kruskal-Walis test examined for significance of non-normal distributions of continuous variables with Dunn's comparison used for post hoc analysis. Pearson's Chi Square was used to assess relationships between two categorical variables. Univariate analysis was used to evaluate continuous variables by incorporating covariates with Bonferroni post hoc test for pairwise comparison. Binary logistic regression analysis identified dietitian's accessibility and center sector associated with nutrition parameters achieving the Kidney Disease Outcomes Quality Initiative (KDOQI) recommendations [14]. Statistical analyses were computed using the IBM SPSS version 
26.0 (IBM SPSS Statistics Inc. Chicago IL. USA) and statistical significance level was set as $p<0.05$.

\section{Results}

\section{$\mathrm{HD}$ center distribution and dietitian access}

Of 153 HD centers contacted, 3 centers refused to participate, leaving only $150 \mathrm{HD}$ centers for respondent inclusion. The characteristics of these HD centers are summarized in Table 1. By sector distribution, private centers $(57.3 \%)$ dominated over government $(22.7 \%)$ and NGO (20.0\%) centers. Regionally the HD center distribution was as per the Central region $(28.0 \%)>$ Northern region $(23.3 \%)>$ East Coast $(21.3 \%)>$ Borneo $(14.0 \%)>$ Southern region (13.0\%). Majority reported lack of dietitians with only $18.0 \%$ reporting access to a dedicated dietitian and $14.7 \%$ having access to a visiting or shared dietitian. Most government centers had access to either dedicated, visiting or shared dietitians contrasting with poor access to a dietitian in both private $(84.9 \%)$ and NGO (73.3\%) HD centers. In particular, no NGO center had access to dedicated dietitian service. Lack of dietitian service was noticeable for HD centers in the Southern region (90\%) compared to other regions (ranged from 59.4 to 68.6\%). Number of patients per center with a dedicated dietitian differed significantly from centers without a dietitian $(71.4 \pm 37.8$ vs. $49.5 \pm$ 30.4 respectively, $p=0.005$ ).

\section{Nutrition monitoring and education}

Nutrition monitoring, nutrition education, use of renal specific ONS and provision of in-center meals were nutrition care domains assessed in this situational analysis (Table 2). Serum albumin was used by all HD centers for nutrition monitoring, followed by normalized protein catabolic rate $(n \mathrm{PCR}), \mathrm{BMI}$ and dietary assessment. Neither sector distribution of HD centers nor dietitian access significantly correlated with nutrition monitoring $(p>0.05)$. None of the HD centers reported using any of the available nutrition-screening tools such as Subjective Global Assessment, Malnutrition Inflammation Score or Dialysis Malnutrition Score.

Nurses (100\%) and physicians (99.3\%) were reported to be regularly involved in providing nutrition education in HD centers compared to dietitians (32.0\%). The sector of HD centers significantly correlated in terms of nutrition education provided by a dietitian $\left(x^{2}=43.011, p<0.001\right)$ and were more common in government HD centers (79.4\%) compared to private (15.1\%) or NGO (26.7\%) centers. Nutrition education was primarily provided individually rather than via group sessions or both in all centers. Some noteworthy comments by dialysis managers on nutrition education were:

- "Our medical doctors in charge will provide nutrition education during 3-monthly routine follow-up based on patients' blood investigations" (NGO center in East Coast, center code: 59)

- "We only provide nutrition pamphlets produced by drug companies to patients" (private center in Central region, center code: 25 )

Table 1 Characteristics of participating HD centers

\begin{tabular}{|c|c|c|c|c|}
\hline & \multirow[b]{2}{*}{ All $(n=150)$} & \multicolumn{3}{|l|}{ Dietitian Accessibility } \\
\hline & & Not available $(n=101)$ & Dedicated dietitian $(n=27)$ & Shared/ visiting dietitian $(n=22)$ \\
\hline \multicolumn{5}{|l|}{ By Sector } \\
\hline Government & $34(22.7 \%)$ & $6(17.6 \%)$ & 19 (55.9\%) & $9(26.5 \%)$ \\
\hline NGO & $30(20.0 \%)$ & $22(73.3 \%)$ & - & $8(26.7 \%)$ \\
\hline Private & $86(57.3 \%)$ & $73(84.9 \%)$ & $8(9.3 \%)$ & $5(5.8 \%)$ \\
\hline \multicolumn{5}{|l|}{ By Region } \\
\hline Central & $42(28.0 \%)$ & $27(64.3 \%)$ & $10(23.8 \%)$ & $5(11.9 \%)$ \\
\hline East Coast & $32(21.3 \%)$ & 19 (59.4\%) & $6(18.8 \%)$ & 7 (21.9\%) \\
\hline Northern & $35(23.3 \%)$ & $24(68.6 \%)$ & $5(14.3 \%)$ & $6(17.1 \%)$ \\
\hline Southern & $20(13.3 \%)$ & $18(90.0 \%)$ & $2(10.0 \%)$ & - \\
\hline Borneo & $21(14.0 \%)$ & $13(62.0 \%)$ & $4(19.0 \%)$ & $4(19.9 \%)$ \\
\hline Number of patients/center ${ }^{a}$ & $54.5 \pm 32.1$ & $49.5 \pm 30.4$ & $71.4 \pm 37.8$ & $56.2 \pm 25.6$ \\
\hline$<50$ & $80(53.7 \%)$ & $63(78.8 \%)$ & $7(8.8 \%)$ & $10(12.5 \%)$ \\
\hline $50-100$ & $55(36.9 \%)$ & $29(52.7 \%)$ & $15(27.3 \%)$ & $11(20.0 \%)$ \\
\hline$>100$ & $14(9.4 \%)$ & $8(57.1 \%)$ & $5(35.7 \%)$ & $1(7.1 \%)$ \\
\hline
\end{tabular}

${ }^{a} p<0.05$ using one-way ANOVA test and Bonferroni post hoc test indicated significant difference between dedicated dietitian vs. no dietitian Data is presented as either $n(\%)$ or mean \pm standard deviation

Abbreviation: NGO non-governmental organization 
Table 2 Comparison of nutrition practices by sector and dietitian accessibility across hemodialysis centers

\begin{tabular}{|c|c|c|c|c|c|c|c|}
\hline \multirow[t]{2}{*}{ Nutrition Practices } & \multirow{2}{*}{$\begin{array}{l}\text { All } \\
(n=150)\end{array}$} & \multicolumn{3}{|l|}{ Sector } & \multicolumn{3}{|c|}{ Dietitian Accessibility } \\
\hline & & $\begin{array}{l}\text { Government } \\
(n=34)\end{array}$ & $\begin{array}{l}\text { Private } \\
(n=86)\end{array}$ & $\begin{array}{l}\mathrm{NGO} \\
(n=30)\end{array}$ & $\begin{array}{l}\text { Not available } \\
(n=101)\end{array}$ & $\begin{array}{l}\text { Dedicated dietitian } \\
(n=27)\end{array}$ & $\begin{array}{l}\text { Shared/ visiting } \\
\text { dietitian }(n=22)\end{array}$ \\
\hline \multicolumn{8}{|l|}{ Nutrition Monitoring } \\
\hline BMI & $46(30.7 \%)$ & $15(44.1 \%)$ & $22(25.6 \%)$ & $9(30.0 \%)$ & $26(25.7 \%)$ & $12(44.4 \%)$ & $8(36.4 \%)$ \\
\hline Albumin & $150(100 \%)$ & $34(100 \%)$ & $86(100 \%)$ & $30(100 \%)$ & $101(100 \%)$ & $27(100 \%)$ & $22(100 \%)$ \\
\hline$n P C R$ & $49(32.7 \%)$ & $11(32.4 \%)$ & $28(32.6 \%)$ & $10(33.3 \%)$ & $34(33.7 \%)$ & $9(33.3 \%)$ & $6(27.3 \%)$ \\
\hline Dietary & $9(6.0 \%)$ & $1(2.9 \%)$ & $5(5.8 \%)$ & $3(10.0 \%)$ & $5(5.0 \%)$ & $2(7.4 \%)$ & $2(9.1 \%)$ \\
\hline Nutrition Screening Tool & nil & nil & nil & nil & nil & nil & nil \\
\hline \multicolumn{8}{|c|}{ Who delivers Nutrition Education? } \\
\hline Dietitian & 48 (32.0\%) & $27(79.4 \%)$ & $13(15.1 \%)$ & $8(26.7 \%)$ & nil & 27 (100\%) & $22(100 \%)$ \\
\hline Medical doctor & 149 (99.3\%) & $34(100 \%)$ & $86(100 \%)$ & $29(96.7 \%)$ & 100 (99.0\%) & $27(100 \%)$ & $22(100 \%)$ \\
\hline Nurse & $150(100 \%)$ & $34(100 \%)$ & $86(100 \%)$ & $30(100 \%)$ & $101(100 \%)$ & $27(100 \%)$ & $22(100 \%)$ \\
\hline \multicolumn{8}{|c|}{ How is Nutrition Education delivered? } \\
\hline Individual & $103(68.7 \%)$ & $22(64.7 \%)$ & $62(72.1 \%)$ & $19(63.3 \%)$ & $75(74.3 \%)$ & $17(63.0 \%)$ & $11(50.0 \%)$ \\
\hline Group sessions & $13(8.7 \%)$ & $2(5.9 \%)$ & $10(11.6 \%)$ & $1(3.3 \%)$ & $9(8.9 \%)$ & $1(3.7 \%)$ & $3(13.6 \%)$ \\
\hline Both & $34(22.7 \%)$ & $10(29.4 \%)$ & $14(16.3 \%)$ & $10(33.3 \%)$ & $17(16.8 \%)$ & $9(33.3 \%)$ & $8(36.4 \%)$ \\
\hline \multicolumn{8}{|c|}{ Recommendation for Renal Specific ONS } \\
\hline Yes & $103(68.7 \%)$ & $15(44.1 \%)$ & $67(77.9 \%)$ & $21(70.0 \%)$ & $71(70.3 \%)$ & $19(70.4 \%)$ & $13(59.1 \%)$ \\
\hline Free of charge & $10(9.7 \%)$ & $7(46.7 \%)$ & nil & $3(14.3 \%)$ & $1(1.4 \%)$ & $6(31.6 \%)$ & $3(23.1 \%)$ \\
\hline Buy from dialysis center & $31(30.1 \%)$ & $1(6.7 \%)$ & $21(31.3 \%)$ & $9(42.9 \%)$ & $19(26.8 \%)$ & $6(31.6 \%)$ & $6(46.2 \%)$ \\
\hline Buy from outside & $62(60.2 \%)$ & $7(46.7 \%)$ & $46(68.7 \%)$ & $9(42.9 \%)$ & $51(71.8 \%)$ & $7(36.8 \%)$ & $4(30.8 \%)$ \\
\hline \multicolumn{8}{|l|}{ Provision of In-center Meals } \\
\hline Yes & $92(61.3 \%)$ & $23(67.6 \%)$ & $63(73.3 \%)$ & $7(23.3 \%)$ & $61(60.4 \%)$ & $22(81.5 \%)$ & $10(45.5 \%)$ \\
\hline Full meal & $21(22.8 \%)$ & $15(65.2 \%)$ & $6(9.5 \%)$ & nil & $6(9.8 \%)$ & $11(50.0 \%)$ & $4(40.0 \%)$ \\
\hline Light meal & 71 (77.2\%) & $8(34.8 \%)$ & 57 (90.5\%) & 7 (100\%) & $55(90.2 \%)$ & $11(50.0 \%)$ & $6(60.0 \%)$ \\
\hline
\end{tabular}

Note: Data is reported as $n(\%)$

Abbreviation: $B M I$ body mass index, NGO non-governmental organization, $n P C R$ normalized protein catabolic rate, ONS oral nutrition supplement

- "Nutrition education will be given as part of the overall health education module given to patients" (private center in East Coast, center code 114)

- "Our dedicated nurses have undergone training on nutrition management of dialysis patients and we have regular meetings to discuss about nutrition issues of patients" (NGO center in Southern region, center code: 45)

\section{Renal specific ONS}

Recommending use of renal specific ONS was reported by $68.7 \%$ of HD centers, which significantly correlated with HD sector $\left(\chi^{2}=12.961, p=0.002\right)$. It was more common in private $(77.9 \%)$ and NGO $(70.0 \%)$ centers compared to government (44.1\%) centers. However, only 9.7\% of HD centers provided ONS at no cost to patients but none by private centers. Figure 1 lists the indications and contraindications by dialysis managers for recommending renal specific ONS to patients.

\section{In-center meals provision}

All HD centers allowed patients to eat during treatment, but $10(6.7 \%)$ centers advised against heavy meal consumption. Provision of in-center meals was significantly correlated by sector $\left(x^{2}=23.584, p<0.001\right)$ and dietitian access $\left(\chi^{2}=8.529, p=0.014\right)$, with NGO centers $(23.3 \%)$ and centers with visiting dietitians (40.9\%) having a lower frequency of in-center meals provision (Table 2). Twelve HD centers provided menus of in-center meals served during treatment with menu rotations ranging between 3 to 14 days. The nutrient content (means \pm standard deviations) of these in-center meals provided in 12 HD centers were $469.1 \pm 108.5 \mathrm{kcal}, \quad 57.0 \pm 18.8 \mathrm{~g}$ carbohydrate, $24.8 \pm 8.7 \mathrm{~g}$ protein, $15.6 \pm 7.3 \mathrm{~g}$ fat, 400.0 $\pm 497.3 \mathrm{mg}$ sodium, $519.0 \pm 225.0 \mathrm{mg}$ potassium, $281.9 \pm$ $164.6 \mathrm{mg}$ phosphorus, and $322.1 \pm 86.0 \mathrm{ml}$ fluid.

\section{Nutrition outcomes of patients}

Four out of 150 participating centers did not submit patients' annual data to NRR, and 2679 patients' annual data 


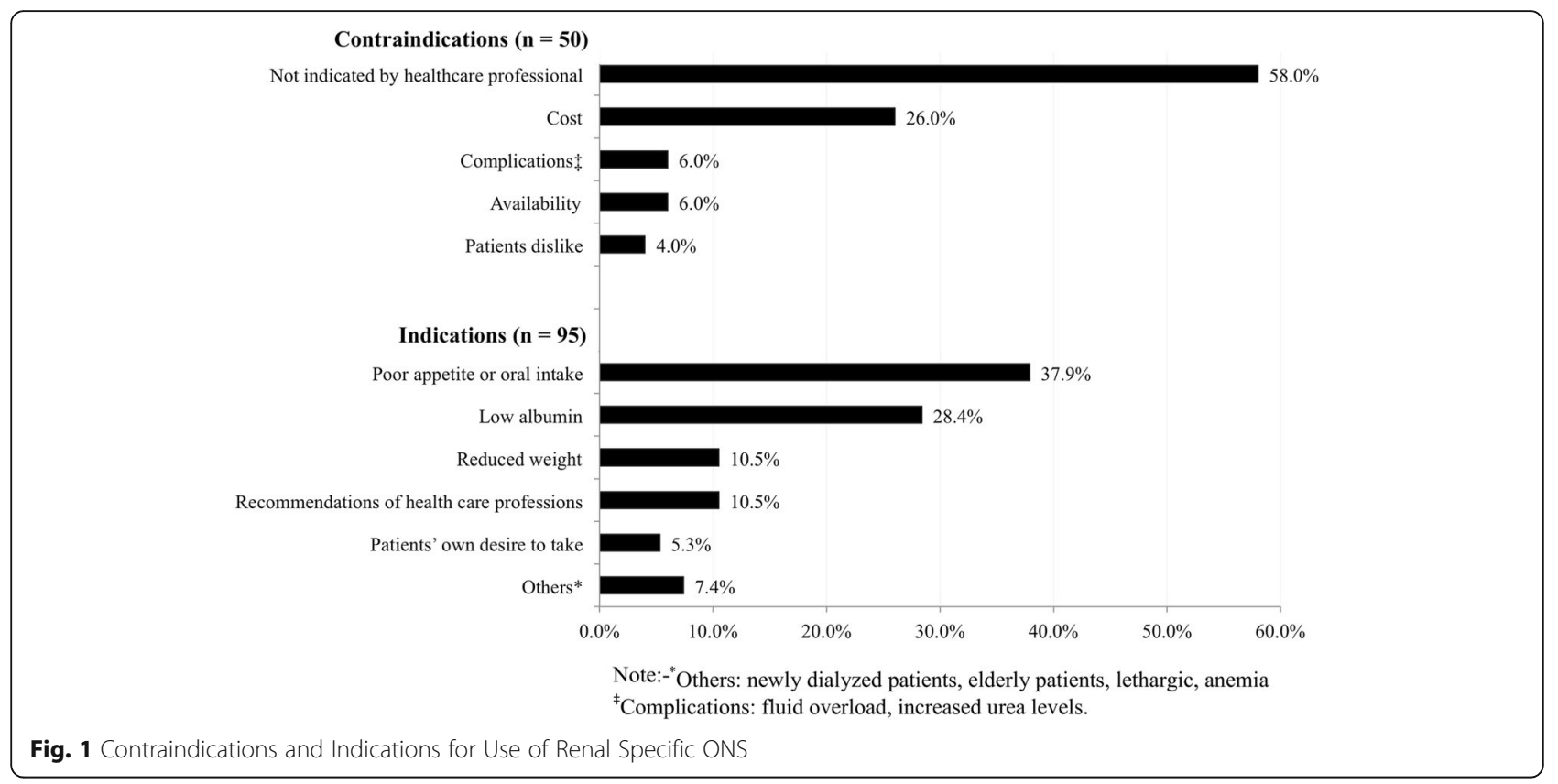

from the remaining 146 centers were incomplete, leaving only annual data of 4362 patients available for statistical analysis. Patients' characteristics and nutrition parameters are summarized in Table 3. Pre-dialysis serum creatinine was significantly lower in centers with access to a dietitian compared to without a dietitian $(p=0.004)$ whereas center sector variation was not a factor $(p=0.431)$. On the other hand, BMI significantly differed by sector, with higher BMI values prevalent in patients from private centers compared to government $\left(24.6 \mathrm{~kg} / \mathrm{m}^{2}\right.$ vs. $\left.23.5 \mathrm{~kg} / \mathrm{m}^{2}, p<0.001\right)$ and NGO centers $\left(24.6 \mathrm{~kg} / \mathrm{m}^{2}\right.$ vs. $\left.23.8 \mathrm{~kg} / \mathrm{m}^{2}, p=0.003\right)$. Serum albumin levels also significantly differed by sector with patients from private HD centers having significantly lower serum albumin levels compared to patients from NGO centers $(38.6 \mathrm{~g} / \mathrm{L}$ vs. $39.4 \mathrm{~g} / \mathrm{L}, p<0.001)$. Serum phosphorus levels were also significantly different by sector and dietitian accessibility. Serum phosphorus levels were lowest in patients from government centers, followed by NGO and private centers $(1.62 \mathrm{mmol} / \mathrm{L}$ vs. $1.78 \mathrm{mmol} / \mathrm{L}$ vs. 1.84 $\mathrm{mmol} / \mathrm{L}$ ). Contrarily, significant higher phosphorus levels were observed in patients with access to a shared or visiting dietitian compared to a dedicated dietitian $(1.79 \mathrm{mmol} /$ L vs. $1.74 \mathrm{mmol} / \mathrm{L}, p<0.001)$ or no dietitian $(1.79 \mathrm{mmol} / \mathrm{L}$ vs. $1.74 \mathrm{mmol} / \mathrm{L}, p<0.001)$.

These nutrition parameters were then categorized in accordance with achievement of the KDOQI recommendations [14] namely, pre-dialysis serum creatinine $\geq 884 \mu \mathrm{mol} /$ $\mathrm{L}, \mathrm{BMI} \geq 25.0 \mathrm{~kg} / \mathrm{m}^{2}$, serum albumin $\geq 40 \mathrm{~g} / \mathrm{L}$, and serum phosphorus $\leq 1.78 \mathrm{mmol} / \mathrm{L}$ (Table 4). Both sector and dietitian accessibility was not associated with achieving albumin $\geq 40 \mathrm{~g} / \mathrm{L}$. However, patients from NGO centers were $36 \%$ more likely (95\% CI: $1.03,1.81 ; p=0.030)$ to achieve pre-dialysis serum creatinine $\geq 884 \mu \mathrm{mol} / \mathrm{L}$ compared to patients from government centers, while patients from centers with dedicated dietitian service were $29 \%$ less likely (95\% CI: $0.54,0.94 ; p=0.017$ ) to achieve pre-dialysis serum creatinine $\geq 884 \mu \mathrm{mol} / \mathrm{L}$ than patients from centers without access dietitian services. In terms of BMI, patients of private center were $32 \%$ more likely ( $95 \%$ CI: 1.04, 1.67; $p=0.022)$ to achieve $\mathrm{BMI} \geq 25.0 \mathrm{~kg} / \mathrm{m}^{2}$ compared to government centers, whilst dietitian access was not a related factor $(p>0.05)$. Private patients were $62 \%$ less likely $(95 \%$ CI: $0.30,0.45 ; p<0.001$ ) while NGO patients were $56 \%$ less likely (95\% CI: $0.34,0.56 ; p<0.001)$ to achieve serum phosphorus control compared to government patients. Patients from centers with a shared/visiting dietitian had 35\% lower probability (95\% CI: $0.53,0.81 ; p<0.001$ ) to achieve serum phosphorus levels below $1.78 \mathrm{mmol} / \mathrm{L}$ compared to centers without access to a dietitian.

\section{Discussion}

This is the first situational analysis carried out on a national scale using randomized sampling of HD centers registered with the NRR, enabling adequate regional representation of the total sampling distribution. The state of renal nutrition practice reported in this study may reflect a similar scenario in other Southeast and South Asian countries, where access to a dietitian may be limited [6]. In Malaysia, overall dietitians' accessibility (either dedicated, visiting or shared) was available only to $32.7 \%$ of HD centers, and this accessibility was restricted to larger urban centers and particularly government centers. In Europe, the availability of dietitians in HD centers ranges between 20\% in Spain to $85 \%$ in the UK [15] while it is 


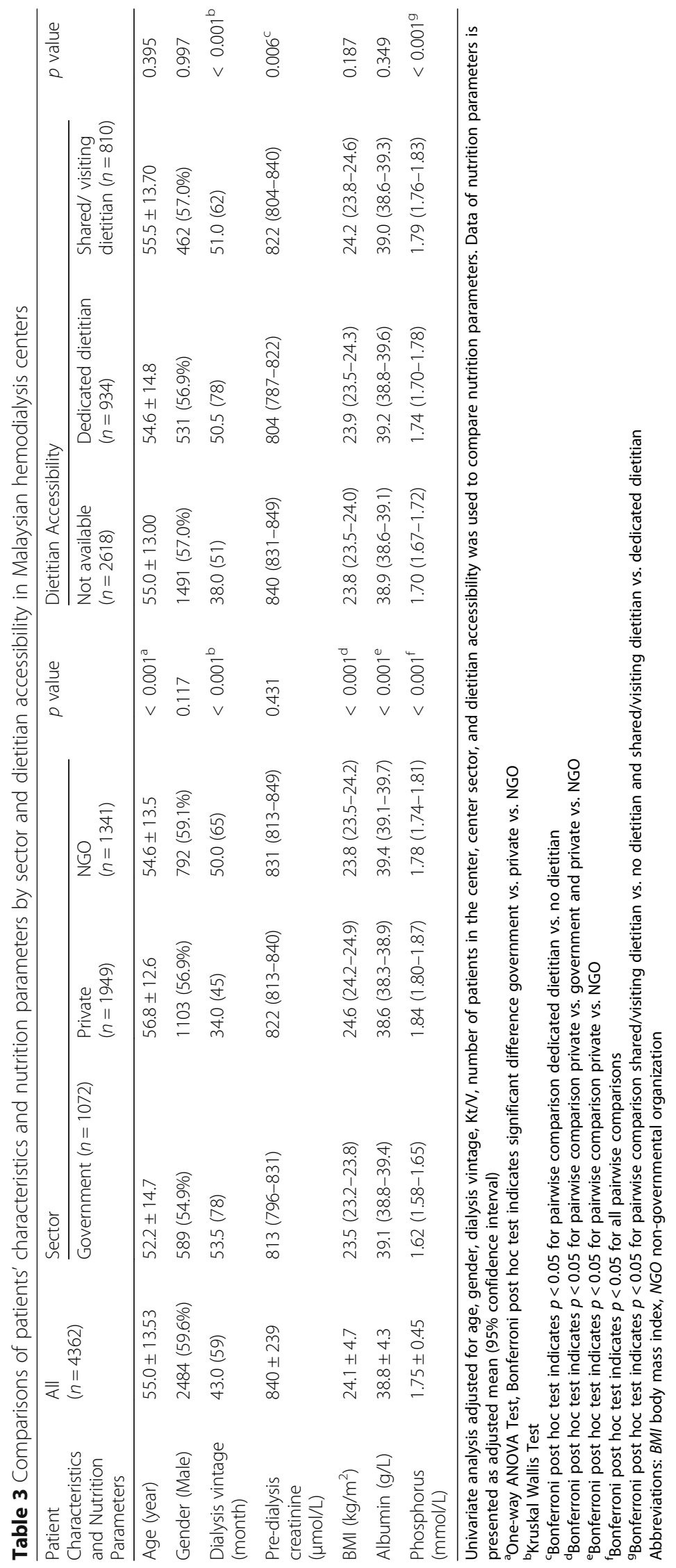


Table 4 Adjusted odds ratio by hemodialysis center sector and dietitian accessibility for achieving KDOQI nutritional outcomes

\begin{tabular}{|c|c|c|c|c|c|c|c|c|}
\hline & \multicolumn{2}{|c|}{ Serum Creatinine $\geq 884 \mu \mathrm{mol} / \mathrm{L}$} & \multicolumn{2}{|l|}{$\mathrm{BMI} \geq 25 \mathrm{~kg} / \mathrm{m}^{2}$} & \multicolumn{2}{|c|}{ Serum Albumin $\geq 40 \mathrm{~g} / \mathrm{L}$} & \multicolumn{2}{|c|}{ Serum Phosphorus $\leq 1.78 \mathrm{mmol} / \mathrm{L}$} \\
\hline & $\overline{\mathrm{OR}} \mathrm{adj}(95 \% \mathrm{Cl})$ & $p$ value & $\overline{\mathrm{OR}_{\mathrm{adj}}(95 \% \mathrm{Cl})}$ & $\overline{p \text { value }}$ & $\mathrm{OR}_{\text {adj }}(95 \% \mathrm{Cl})$ & $\overline{p \text { value }}$ & $\overline{\mathrm{OR}_{\mathrm{adj}}(95 \% \mathrm{Cl})}$ & $p$ value \\
\hline \multicolumn{9}{|l|}{ HD Sector } \\
\hline Private & $1.25(0.96,1.63)$ & 0.103 & $1.32(1.04,1.67)$ & 0.022 & $0.97(0.76,1.25)$ & 0.124 & $0.38(0.30,0.45)$ & $<0.001$ \\
\hline NGO & $1.36(1.03,1.81)$ & 0.030 & $0.95(0.74,1.22)$ & 0.688 & $0.83(0.66,1.05)$ & 0.827 & $0.44(0.34,0.56)$ & $<0.001$ \\
\hline Government & 1.00 & & 1.00 & & 1.00 & & 1.00 & \\
\hline \multicolumn{9}{|l|}{ Dietitian Accessibility } \\
\hline Shared/visiting dietitian & $0.85(0.67,1.08)$ & 0.074 & $1.13(0.91,1.41)$ & 0.281 & $1.18(0.95,1.46)$ & 0.129 & $0.65(0.53,0.81)$ & $<0.001$ \\
\hline Dedicated dietitian & $0.71(0.54,0.94)$ & 0.017 & $0.87(0.68,1.12)$ & 0.260 & $1.05(0.82,1.34)$ & 0.689 & $0.78(0.61,1.00)$ & 0.052 \\
\hline No dietitian & 1.00 & & 1.00 & & 1.00 & & 1.00 & \\
\hline
\end{tabular}

Note- Binary logistic regression adjusted for age, gender, dialysis vintage, Kt/V, number of patients in the center, center sector, and dietitian accessibility Abbreviations: BMI Body Mass Index, HD hemodialysis NGO Non-governmental organization, OR $R_{a d j}(95 \%$ Cl) adjusted odd ratio ( $95 \%$ confidence interval)

mandatory for dialysis facilities in the United States to have a dietitian member in the multidisciplinary team for patient care [16]. Despite more than 50\% of HD delivery in Malaysia being dominated by private centers, patients in these centers had a more limited access to a dietitian compared to patients in government or NGO centers. Several factors may lead to limited dietitian accessibility in private centers: (i) dietitian service is not mandatory for private HD centers in Malaysia, but nephrologists and nurses are considered essential in patient care [17] (ii) patients dialyzed in private centers are paying more for the dialysis treatment, and therefore unable to pay out-of-pocket consultations for the dietitian as this fee is not reimbursed by insurance and (iii) most small scale private centers cannot afford the wage cost for a full time dietitian.

Nutrition assessment is an essential and fundamental component to identify patients with critical nutrition issues such as PEW [18]. As expected, we found nutrition assessment practices were relatively uniform across different HD sectors with reliance on serum albumin as the standard monitoring parameters. A shortcoming in relying on albumin alone to identify malnutrition, without validating with BMI and dietary intake, is the risk of potential false negatives arising from inflammation, fluid overload and infection [19, 20]. Although all centers used serum albumin as a reference nutritional marker, alarmingly only one-third of centers added monitoring data for BMI and $n \mathrm{PCR}$. BMI is a simple and inexpensive nutrition assessment tool, which correlates with clinical outcomes in HD patients [21] while $n$ PCR is already used as a proxy of estimating dietary protein intake by $38 \%$ of HD centers in Europe [15]. We also found that overall, dietary assessment was rarely performed and no HD centers reported using any nutrition-screening tool, irrespective of dietitian accessibility. A thorough dietary assessment is critical as it allows personalized advice to be provided to dialysis patients with various nutrient restrictions [22]. The non-participation of dietitians in performing regular nutrition assessment was observed even in HD centers with dietitian access, as dietitians only 'take care' of patients who had been pre-screened and referred by other healthcare professionals. Therefore, it is not surprising that we could not establish any relationship between dietitian accessibility and nutrition assessment practices. Moreover, the absence of a dietitian means lack of expertise and skills in performing certain nutrition assessments such as handgrip strength, skinfold measurement and dietary interviews [23].

The algorithm for nutritional management of PEW patient by International Society of Renal Nutrition and Metabolism recommends optimizing calorie and protein intakes by providing nutritional support [15]. We therefore, also assessed the practice of renal specific ONS use in these centers. Dialysis managers reported indications for products use for HD patients but we found that some of the indications did not fit the criteria for use [24]. Perceptions of dialysis managers were patients were well nourished despite the lack of proper nutrition assessment along with a view of increased cost burden to patient cost burden are likely obstacles hindering the long terms use of ONS to optimizing nutrition for PEW patients. Despite this negativity, a small percentage of HD centers provided the renal specific ONS free of charge to the patients.

Eating during dialysis is common in all Malaysian HD centers, which is also similar to other countries [25]. It has been suggested that eating during dialysis may lead to complications such as postprandial hypotension, gastrointestinal symptoms, choking and reduced treatment efficiency [26]. However, in practice, these issues have not been often observed in our settings. On the contrary, eating during dialysis has been suggested to improve nutritional status, quality of life, and inflammation status as well as to provide teaching opportunities to patients [26].

It has been conclusively shown that dietitians' care improves nutrition and clinical outcomes of HD patients [27- 
29]. In addition, dietitians have other important roles in HD centers such as knowledge sharing with co-health care professionals, quality assessment and performance improvement, research, and protocol/algorithm development and monitoring, which may indirectly translate into improved patients' nutrition outcomes [5]. We attempted to compare the nutrition outcomes between centers with dietitian access and centers without dietitian access but we did not observe favorable nutrition outcomes associated with dietitian accessibility. There are some possible explanations for this observation. In Malaysia, dietitians are not routinely involved in the clinical practice at HD centers and only attend to selected patients based on physician referral. In addition, the norm in Malaysia is dietitians are assigned to cover several areas including the food service, inpatient management, as well as chronic disease management in outpatient settings. The heavy workload imposed on a dietitian may hinder them from proactively attending to all patients in HD centers. In this context, accessibility to a dietitian does not necessarily translate into more contact time with the patient. Therefore, our findings do not refute the importance of dietitians' involvement in patient care. Instead, it calls for a strategic human resource management to allow dietitians to be more proactive in routine nutrition management in HD centers.

Marginally lower albumin levels were noted in patients from private HD centers compared to NGO centers but all center mean values were still close to the reference target of $40 \mathrm{~g} / \mathrm{L}$ [14]. Serum phosphorus levels were observed to vary according to HD sector and likely affected by type of phosphorus binder prescription and dialysis regimes [30]. In Malaysia, government HD centers are known to be resourceful in achieving outcome-based goals targeting hyperphosphatemia, and medical teams without dietitians (nephrologists and nurses) are willing to optimize nutrition guidelines (personal communication from BLG and $S B$ ). Dietitian accessibility as indicated by this survey meant relying on visiting dietitians to optimize phosphorus control was not better than without a dietitian at all. This perhaps can be attributed to visiting dietitians only providing group education to patients rather than individual patient-centered care as well as a lack of follow-up in the Malaysian scenario. In fact, intensive intervention by dietitians is required for effective phosphorus control in the United Kingdom, which is known to have dedicated dietitian services available for renal patient care [31]. Contrarily, nutrition education delivered by dialysis nurses and physicians may also be equally effective in reducing serum phosphorus as reported in China [32]. Tsai et al. [33] have shown that dietary education by dialysis staff alone resulted in reducing serum phosphorus levels of HD patients, but involvement of dietitians provided additional benefits on controlling hyperphosphatemia while Blair et al. [34] did not observe significant difference in serum phosphorus level in HD patients managed by dietitians or non-dietitians (nephrologists and nurses).

Our study had certain strengths and limitations. This was the first study to evaluate nutrition practices in Malaysian HD centers at national level. We collected information from HD centers representative of different sectors and regions. However, this survey relied on information provided by dialysis managers rather than direct evaluation of practices at HD centers. Information on the presence of resident nephrologists, medical treatment details, and dietitians' contact time and competencies were not collected in this survey, which may affect interpretation of the results. Furthermore the NRR database, from which we retrieved patient data, lacked critical information on socioeconomic status which would have allowed us to adjust for confounders in examining the relationship of nutritional outcomes to accessibility of dietitian. However other confounders such as age, gender, dialysis vintage and adequacy were included in the statistical analysis. Moreover, the temporal relationship between dietitian accessibility and nutrition outcomes could not be confirmed due to the cross-sectional design and potential residual confounding factors. Despite the limitations, we have generated results that identified gaps in the current status of nutrition care practice in Malaysian HD centers, which is relevant to inform on the planning of improvement strategies to mitigate these gaps.

This study's findings should inform towards a policy agenda that targets improving dialysis care in Malaysia. As private HD centers continue to increase in Malaysia, this sector is expected to become the major provider of $\mathrm{HD}$ treatment. However, patients receiving HD treatment from these facilities going by this study are less likely to have access to dietitian services. A policy development by the stakeholder is urgently called for, to ensure adequate dietitian accessibility in renal patient care in this dialysis sector, which is fast growing in Malaysia. Another option to explore would be locum dietitian services towards benefiting dialysis patients. However, a major development should be the advancement in renal dietetic skills relevant to chronic kidney disease patient management, which would allow for competency development and credentialing for dietitians. A critical aspect to consider is that holistic patient-centered care should include strategies to detect, intervene and audit outcomes for dialysis patients with poor nutritional status.

\section{Conclusion}

Variability of nutrition practices was observed in Malaysian HD centers and the standard of existing nutrition care was generally unsatisfactory due to lack of attention to patient-centered approaches such as personalized nutrition intervention as well as implementation of standardized nutrition guidelines. A dedicated dietitian in HD centers may 
be essential to standardize nutrition practices and improve nutrition care, which is an important aspect of comprehensive treatment provided to HD patients. Interestingly, nutritional outcome disparities are observed in patients from different HD centers sector, which warrant further investigation.

\section{Additional file}

Additional file 1: A survey on nutrition practices in Malaysian hemodialysis centers. (DOCX $17 \mathrm{~kb})$

\section{Abbreviations}

BMl: Body mass index; HD: Hemodialysis; KDOQI: Kidney Disease Outcomes Quality Initiative; NGO: Non-governmental organization; nPCR: Normalized protein catabolic rate; NRR: National Renal Registry; ONS: Oral nutrition supplement; PEW: Protein energy wasting

\section{Acknowledgements}

B-H. K. is a PhD candidate receiving the Chancellor's Research Scholarship (Zamalah Yayasan Canselor) from Universiti Kebangsaan Malaysia. We thank all dialysis managers and dietitians who participated in this study. Most importantly we appreciate contribution from Ms. Lee Day Guat, senior clinical registry manager of National Renal Registry as well as the collaboration from the National Renal Registry and Malaysian Society of Nephrology in providing patients' data required for this study.

\section{Ethics approval and consent to participate}

The protocol for this study received ethical approval from the Research Ethics Committee, National University of Malaysia (NN-079-2015) and Medical Research Ethic Committee, Ministry of Health, Malaysia (NMRR15-1245-27,039). No informed consent was required as defined by the Institute Review Board.

\section{Funding}

This research did not receive any specific grant from funding agencies in the public, commercial, or not-for-profit sectors.

\section{Availability of data and materials}

The datasets generated and/or analysed during the current study are available from the corresponding author on reasonable request.

\section{Authors' contributions}

B-HK and TK designed the study, acquired, and interpreted the data, as well as drafted the manuscript. KC provided statistical consultation. AHAG, ZM, GA, SB, RV, RY, B-LG, and B-CB provided intellectual content and critical review of the manuscript. All authors have read and approved the manuscript.

\section{Consent for publication}

Not applicable

\section{Competing interests}

The authors declare that they have no competing interests.

\section{Publisher's Note}

Springer Nature remains neutral with regard to jurisdictional claims in published maps and institutional affiliations.

\section{Author details}

${ }^{1}$ Dietetics Program, Faculty of Health Sciences, Universiti Kebangsaan Malaysia, 50300 Kuala Lumpur, Malaysia. ${ }^{2}$ School of Medicine, Faculty of Health and Medical Sciences, Taylor's University, 47500 Subang Jaya, Malaysia. ${ }^{3}$ Department of Medicine, Faculty of Medicine, Universiti Kebangsaan Malaysia Medical Center, 56000 Kuala Lumpur, Malaysia. ${ }^{4}$ National Kidney Foundation of Malaysia, Jalan 14/29, 46100 Petaling Jaya, Selangor, Malaysia. ${ }^{5}$ Department of Nephrology, Kuala Lumpur Hospital, Jalan Pahang, 53000 Kuala Lumpur, Malaysia. ${ }^{6}$ Department of Nephrology, Serdang
Hospital, Jalan Puchong, 43000 Kajang, Selangor, Malaysia. ${ }^{7}$ Department of Nephrology, Selayang Hospital, Lebuh Raya Selayang-Kepong, 68100 Batu Caves, Selangor, Malaysia. ${ }^{8}$ School of BioSciences, Faculty of Health and Medical Sciences, Taylor's University, 1, Jalan Taylors, 47500 Subang Jaya, Malaysia.

Received: 29 August 2018 Accepted: 9 November 2018

Published online: 04 December 2018

\section{References}

1. World Bank Group Malaysia. 2018. https://data.worldbank.org/country/ malaysia. Assessed 5 June 2018

2. Wong HS, BL Goh, eds. Twenty third report of the Malaysian Dialysis and transplant 2015. Kuala Lumpur; 2017.

3. Himmelfarb J, Ikizler TA. Hemodialysis. N Engl J Med. 2010;363(19):1833-45.

4. Brommage D, Karalis M, Martin C, McCarthy M, Benner D, Geoddeke-Merickel $\mathrm{CM}$, et al. American dietetic association and the National Kidney Foundation standards of practice and standards of professional performance for registered dietitians (generalist, specialty, and advanced) in nephrology care. J Ren Nutr. 2009:19(5):345-56.

5. McCann L. Pocket Guide to Nutrition Assessment of the Patient with Kidney Disease: A Concise, Practical Resource for Comprehensive Nutrition Care in Kidney Disease. 5th ed. New York, NY: National Kidney Foundation; 2015

6. Karupaiah T, Morad Z. Perspectives on the nutritional management of renal disease in Asia: people, practice, and programs. J Ren Nutr. 2007;17(1):93-6.

7. Lim TO, Lim YN. Eleventh report of the Malaysian Dialysis and transplant registry 2003. Kuala Lumpur: The National Renal Registry; 2004.

8. Gafor AHA, Karupaiah T, Koh KH, Rahman AFA. Chapter 7: nutritional status on Dialysis. In: Wong HS, Goh BL, editors. Twenty Third Report of the Malaysian Dialysis and Transplant 2015. Kuala Lumpur: The National Renal Registry; 2017. p. 88-97.

9. Fouque D, Kalantar-Zadeh K, Kopple J, Cano P, Chauveau P, Cuppari L, et al. A proposed nomenclature and diagnostic criteria for protein-energy wasting in acute and chronic kidney disease. Kidney Int. 2008;73(4):391-8.

10. Kanazawa Y, Nakao T, Murai S, Okada T, Matsumoto H. Diagnosis and prevalence of protein energy wasting and its association with mortality in Japanese haemodialysis patients. Nephrology. 2017;22(7):541-7.

11. Sahathevan S, Se CH, Ng SH, Chinna K, Harvinder GS, Chee WSS, et al. Assessing protein energy wasting in a Malaysian haemodialysis population using self-reported appetite rating: a cross-sectional study. BMC Nephrol. 2015;16:99. https://doi.org/10.1186/s12882-015-0073-x.

12. Tee $E$, Noor Ml, Azudin M, Idris K. Nutrient composition of Malaysian foods. Kuala Lumpur: Institute of Medical Research; 1997

13. Health Promotion Board 2011. Energy \& Nutrient Composition of food. Singapore https://focos.hpb.gov.sg/eservices/ENCF/ . Assessed 3 May 2018.

14. Kopple JD. National kidney foundation $\mathrm{K} / \mathrm{DOQ}$ clinical practice guidelines for nutrition in chronic renal failure. Am J Kidney Dis. 2001;37(1 Suppl 2):S66-70.

15. Hecking E, Bragg-Gresham JL, Rayner HC, Pisoni RL, Andreucci VE, Combe C, et al. Haemodialysis prescription, adherence and nutritional indicators in five European countries: results from the Dialysis outcomes and practice patterns study (DOPPS). Nephrol dial transplant. 2004;19(1):100-7.

16. Centers for Medicare and Medicaid Services (CMS) HHS. Medicare and medic aid programs; conditions for coverage for end-stage renal disease facilities; final rule. Fed Regist. 2008;73:20369-484.

17. Medical Practice Division, Ministry of Health Malaysia. Standard for Private Hemodialysis Unit. http://medicalprac.moh.gov.my/v2/modules/ mastop_publish/?tac=PELAN_LANTAI_DAN_LAWATAN_PEMERIKSAAN Accessed 11 Oct 2018.

18. Ikizler TA, Cano NJ, Franch H, Fouque D, Himmelfarb J, Kalantar-Zadeh K, et al. Prevention and treatment of protein energy wasting in chronic kidney disease patients: a consensus statement by the International Society of Renal Nutrition and Metabolism. Kidney Int. 2013;84(6):1096-107.

19. Bharadwaj S, Ginoya S, Tandon P, Gohel TD, Guirguis J, Vallabh H, et al. Malnutrition: laboratory markers vs nutritional assessment. Gastroentero Rep. 2016;4(4):272-80.

20. Vergili JM, Wolf RL. Nutrition practices of renal dietitians in hemodialysis centers throughout the United States: a descriptive study. Ren Nutr. 2010;20(1):8-16.

21. Badve SV, Paul SK, Klein K, Clayton PA, Hawley CM, Brown FG, et al. The association between body mass index and mortality in incident dialysis patients. PLoS One. 2014;9(12):e114897. 
22. Bross R, Noori N, Kovesdy CP, Murali SB, Benner D, Block G, et al. Dietary assessment of individuals with chronic kidney disease. Semin Dial. 2010;23(4):359-64.

23. Bellizzi V, Di lorio BR, Brunori G, De Nicola L, Minutolo R, Conte G, et al. Assessment of nutritional practice in Italian chronic kidney disease clinics: a questionnaire-based survey. J Ren Nutr. 2010;20(2):82-90

24. Ikizler TA. Optimal nutrition in hemodialysis patients. Adv Chronic Kidney Dis. 2013;20(2):181-9.

25. Kistler B, Benner D, Burgess M, Stasios M, Kalantar-Zadeh K, Wilund KR. To eat or not to eat-international experiences with eating during hemodialysis treatment. J Ren Nutr. 2014;24(6):349-52.

26. Kistler BM, Benner D, Burrowes JD, Campbell KL, Fouque D, Garibotto G, et al. Eating during hemodialysis treatment: a consensus statement from the International Society of Renal Nutrition and Metabolism. J Ren Nutr. 2018; 28(1):4-12.

27. Garagarza CA, Valente AT, Oliveira TS, Caetano CG. Effect of personalized nutritional counseling in maintenance hemodialysis patients. Hemodial Int. 2015;19(3):412-8.

28. Lopes AA, Bragg-Gresham JL, Elder SJ, Ginsberg N, Goodkin DA, Pifer T, et al. Independent and joint associations of nutritional status indicators with mortality risk among chronic hemodialysis patients in the Dialysis outcomes and practice patterns study (DOPPS). J Ren Nutr. 2010;20(4):224-34.

29. Slinin Y, Guo H, Gilbertson DT, Mau LW, Ensurd K, Collins AJ, et al. Prehemodialysis care by dietitians and first-year mortality after initiation of hemodialysis. Am J Kidney Dis. 2011;58(4):583-90.

30. Cupisti A, Gallieni M, Rizzo MA, Caria S, Meola M, Bolasco P. Phosphorus control in dialysis. Int J Nephrol Renovasc Dis. 2013;6:193-205.

31. Morey B, Walker R, Davenport A. More dietetic time, better outcome? Nephron Clin Pract. 2008;109(3):173-80.

32. Shi YX, Fan XY, Han HJ, Wu QX, Di HJ, Hou YH, et al. Effectiveness of a nurse-led intensive educational programme on chronic kidney failure patients with hyperphosphataemia: randomised controlled trial. J Clin Nurs. 2013;22(7-8):1189-97.

33. Tsai WC, Yang JY, Luan CC, Wang YJ, Lai YC, Liu LC, et al. Additional benefit of dietitian involvement in dialysis staffs-led diet education on uncontrolled hyperphosphatemia in hemodialysis patients. Clin Exp Nephrol. 2016;20(5):815-21.

34. Blair D, Byham-Gray L, Sweet SJ, Denmark R, Parott JS, Lewis E, et al. Effect of a dietitian-managed bone algorithm on serum phosphorus level in maintenance hemodialysis patients. J Ren Nutr. 2013;23(2):98-105.

Ready to submit your research? Choose BMC and benefit from:

- fast, convenient online submission

- thorough peer review by experienced researchers in your field

- rapid publication on acceptance

- support for research data, including large and complex data types

- gold Open Access which fosters wider collaboration and increased citations

- maximum visibility for your research: over $100 \mathrm{M}$ website views per year

At BMC, research is always in progress.

Learn more biomedcentral.com/submissions 